Research Article

\title{
Graphene Oxide as a Nanocarrier for Controlled Loading and Targeted Delivery of Typhonium giganteum Drugs
}

\author{
Xiaohua Gu $\mathbb{D}^{1},{ }^{1}$ Rui Cao $\mathbb{D}^{D},{ }^{1}$ Fu Li, ${ }^{1}$ Yan Li $\mathbb{D}^{1},{ }^{1}$ Hongge Jia, ${ }^{1}$ and Hui Yu ${ }^{2}{ }^{2}$ \\ ${ }^{1}$ College of Materials Science and Engineering, Qiqihar University, Qiqihar 161006, China \\ ${ }^{2}$ College of Textile Materials and Engineering, Wuyi University, Jiangmen 529000, China \\ Correspondence should be addressed to Rui Cao; cao_rui0459@163.com
}

Received 18 May 2018; Revised 24 July 2018; Accepted 9 August 2018; Published 26 September 2018

Academic Editor: Ewa Schab-Balcerzak

Copyright (c) 2018 Xiaohua Gu et al. This is an open access article distributed under the Creative Commons Attribution License, which permits unrestricted use, distribution, and reproduction in any medium, provided the original work is properly cited.

In this study, Typhonium giganteum containing dual-function nanofibers composed of poly(butylene carbonate), polylactic acid, and graphene oxide (PBC/PLA/GO) were successfully fabricated by electrospinning. The results from thermogravimetric analysis (TG), differential scanning calorimetry (DSC), and Fourier-transform infrared spectroscopy (FTIR) indicate that no interactions occurred between PBC and PLA. The nanofiber microstructure upon which graphene oxide was evenly distributed was studied by scanning electron microscopy (SEM) and showed good silk properties. The nanofibers can be used as a drug carrier since loaded Typhonium giganteum fibers possess excellent biocompatibility. Such nanofibers are effective in inhibiting the proliferation of A549 lung cancer cells, and thus they have potential for replacing chemotherapy-based treatments of lung cancer. In addition, the PBC/PLA/GO nanofibers degrade in physiological and natural environments, which is an important feature when engineering tissues and environment-friendly materials.

\section{Introduction}

In recent years, the development of biocompatible nanomaterials has become a popular research topic. Electrospun fibers can mimic the microenvironments of cells and can be beneficial for cell attachment, proliferation, and differentiation. Many kinds of biological scaffold-manufacturing technologies exist, with electrospinning a commonly used method [1]. Electrospinning has several key features: it is simple to use, affordable to implement, can be applied to a wide selection of materials and with very high surfacevolume ratios, can accommodate adjustable porosity, and is sufficiently flexible to adopt a wide range of sizes and shapes. It fabricates nonwoven fabrics and superfine nanofibers tens of nanometers in diameter and provides evaluation of the manufacturing technologies of fibers with plain nonwoven fabrics [2]. Electrospinning uses high-voltage electricity to spray polymer solutions or melt in a strong electric field. As the electric field increases and as the electrostatic force exceeds the surface tension, the polymer solution forms a fiber jet. In the jet and its fiber extension, attracted fibers then fall on the collector [3]. Studies have shown that fiber scaffolds offer more advantages over nonfibrous scaffolds. For instance, drug carrier membranes composed of composite nanofibers have been successfully prepared by this technique, and infrared spectra transmission electron microscopy and X-ray diffraction (XRD) have shown that the drug is well distributed in PLA/PBC composite nanofibers [4]. Analysis of relative contact angles indicate that the composite film was characterized in part by good hydrophilicity and biocompatibility [5]. The PVA/CS nanofibrous membranes which loaded with anticancer drugs can inhibit the growth of cancer cells. Such nanofiber matrices not only function similar to those in releasing anticancer drugs but also induce the regeneration of damaged tissue [6]. Therefore, the loaded drugs nanofiber membranes have been extensively studied in drug delivery systems, small wound dressing, patches, and tissue engineering scaffolds. Many materials including synthetic polymer (such as aliphatic polyesters) and natural macromolecules (such as collagen, fibroin, sodium alginate, and gelatin) were used by electrospinning [7-10]. In addition, functional composite fibers 
have been obtained by introducing metal particles into electrospun fibers [11]. In the medical profession, however, their use is still relatively rare. In pharmaceutical technology, by studying relevant literature, it may be possible to develop methods for releasing drugs from nonwoven fabrics, which would be beneficial in medical applications [12].

Typhonium giganteum is one of the herbs which had high medicinal value as a traditional Chinese medicine. The $T$. giganteum tubers were often used to treat cancer by people who believed in Chinese folk [13]. Recently, more and more studies have shown that the extraction of Typhonium giganteum tubers can inhibit the growth of cancer cells [14-17]. The chemical components of Typhonium giganteum tubers have been reported in some articles; some of them such as $\beta$-sitosterol and lignin compounds have been clearly identified as antitumor components [18]. Hence, T. giganteum tubers are potential drugs which can be used to treat cancer. Graphene oxide (GO) is a single layer of carbon nanomaterial composed of $\mathrm{sp}^{2}$ hybridized carbon atoms obtained by chemical oxidation of graphite powder because its surface can provide a large number of $\pi-\pi$ and hydrogenbond binding sites, and it was often studied as a carrier of antitumor drugs in recent years [19-21].

In this paper, two biodegradable materials, poly(lactic acid) (PLA) and poly(butyl acrylate) (PBC), were chosen to construct PLA/PBC/GO fibers. The resulting fibers can be used as carriers for anticancer agents in ethanol extracts of Typhonium giganteum, and a preliminary study was performed on the chemotherapy of lung cancer using graphene oxide and an ethanol extract of Typhonium giganteum with incorporated fibers. The nanofiber matrix can support the dual functions of cell imaging and drug delivery and may be of significant potential in biomedical application.

\section{Materials and Methods}

2.1. Raw Material. Poly(lactic acid) is a commercial polylactide resin that is an Ingeo biopolymer supplied by NatureWorks LLC Co. (product code: 3051D). Poly(butylene carbonate) (PBC) was supplied by Jiangsu Sanfangxiang Group. Trifluoroacetic acid was supplied by Tianjin Kemiou Chemical Reagent Co., Ltd., China. Graphene oxide was synthesized from graphite powder (325 mesh, Aladdin) using a modified Hummers' method.

2.2. Preparation of Electrostatic Spinning Film. The PLA and $\mathrm{PBC}$ particles were dissolved in a trifluoroacetic acid solvent at a ratio of 2:1 to which ethanolic extract of Typhonium giganteum extract (TGE) was added. The mixture was stirred at $70^{\circ} \mathrm{C}$ for 12 hours using a magnetic stirrer until it was uniformly dissolved, and then 20,40 , and $60 \mathrm{mg}$ of graphene oxide were added in stages to prepare nanofibers. Each prepared solution was placed in a $5 \mathrm{~mL}$ syringe fitted with a $0.55 \mathrm{~mm}$ diameter syringe with aluminum foil as the receiver. The syringe containing the PLA/PBC/graphene oxide solution was cephalosporin fixed and its position was adjusted so that the nanofibers were uniformly injected into the receiver. The positive voltage was $16 \mathrm{kV}$ and the negative

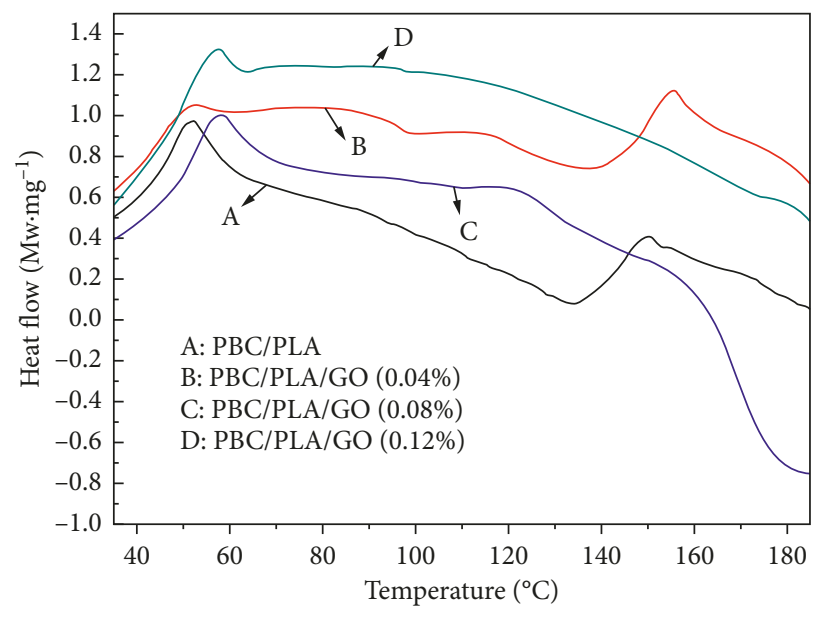

Figure 1: DSC curves of GO/PLA/PBC nanofibers.

voltage was $-6 \mathrm{kV}$, and the syringe was kept at a distance of $15 \mathrm{~cm}$ from the surface. Injection speed was $0.5 \mathrm{~mm} / \mathrm{min}$. The ethanol extract of PLA/PBC nanofibers containing giant PLA was dissolved in PLA solution. Electrospinning was performed as described above. The electrospun membrane containing the TGE was treated with a clear solution, and then, the lung cancer cells were cultured on the surface. Finally, the apoptosis of the cancer cells was observed under a light microscope.

2.3. DSC and SEM Analyses. Differential scanning calorimetry (DSC) was performed with a Q2000 TA, and samples of all produced nanofibers were heated from room temperature to $600^{\circ} \mathrm{C}$ at a rate of $10^{\circ} \mathrm{C} / \mathrm{min}$. A scanning electron microscope (SEM) (Hitachi S-4300, Japan) was used to record and analyze the brittle fracture surface obtained by the application of liquid nitrogen.

2.4. FTIR Spectra. Using attenuated total reflection Fourier infrared spectroscopy (ATR-FTIR, Nicolet Nexus 670 infrared spectrometer), the electrospun PLA, PBC, and graphene oxide fiber structures were characterized by their IR spectral wave numbers from 500 to $4000 \mathrm{~cm}^{-1}$.

2.5. MTT Method to Detect the Proliferation of A549 Cells in Different Membranes. A549 lung cancer cells were removed from cryo-preserved tubes, in a $39^{\circ} \mathrm{C}$ water bath, and melted completely. The cell fluid was removed by adding the cells into an RPMI 1640 (GIBCO) medium containing 10\% fetal bovine serum (FBS). Bottles containing cells were placed in an environment held at $37^{\circ} \mathrm{C}$ with $5 \% \mathrm{CO}_{2}$-saturated humidity. Note that, in order to enhance cell growth, the recovery time is typically $20-24 \mathrm{~h}$. After $2-3$ days, the status of cell growth was observed by using an optical microscope. When A549 cells showed good logarithmic growth, the cell density was adjusted to $2.5 \times 10^{4} / \mathrm{mL}$ using Dulbecco's Modified Eagle Medium (DMEM), and $200 \mu \mathrm{L}$ of the A549 cell suspension was seeded in each well of a 96-well plate 


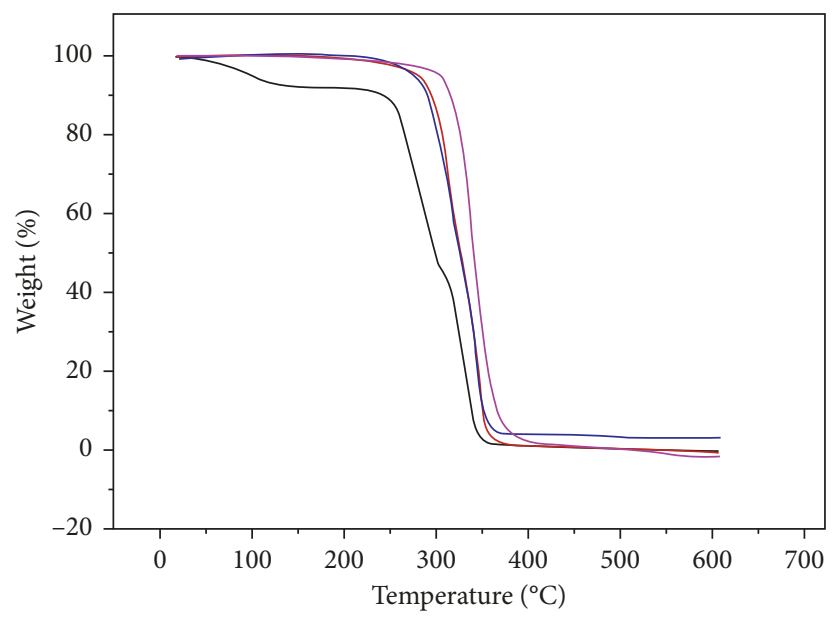

$\begin{array}{ll}\text { — A: PLA/PBC } & \text { C: PLA/PBC/GO }(0.08 \%) \\ \text { — B: PLA/PBC/GO (0.04\%) } & \text { D: PLA/PBC/GO }(0.12 \%)\end{array}$

FigURE 2: TG thermograms of GO/PLA/PBC nanofibers.

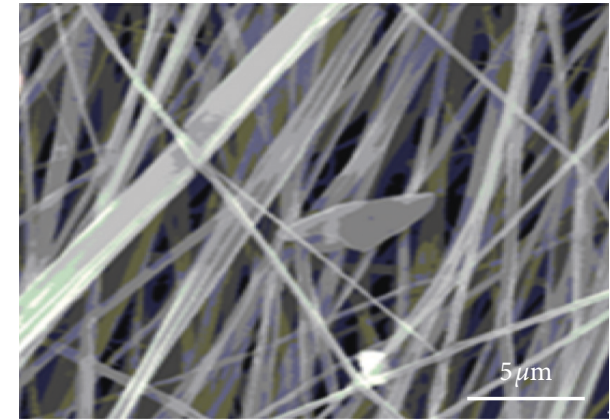

(a)

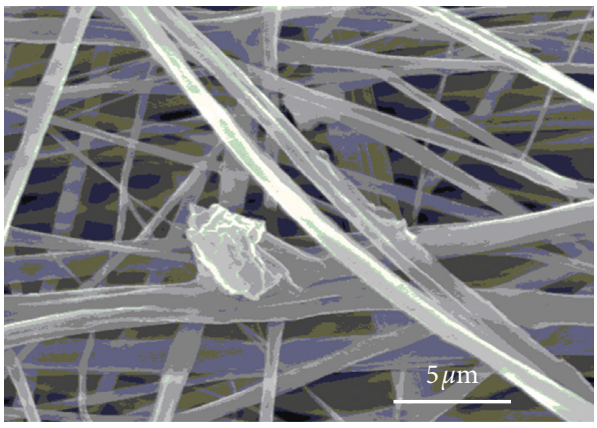

(c)

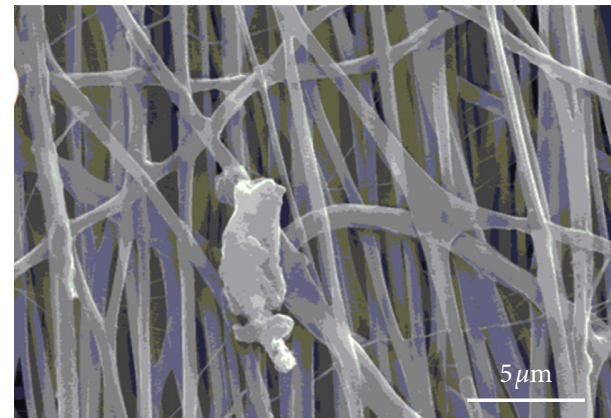

(b)

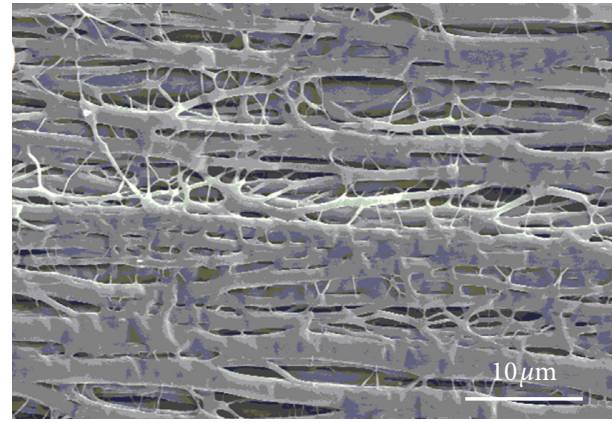

(d)

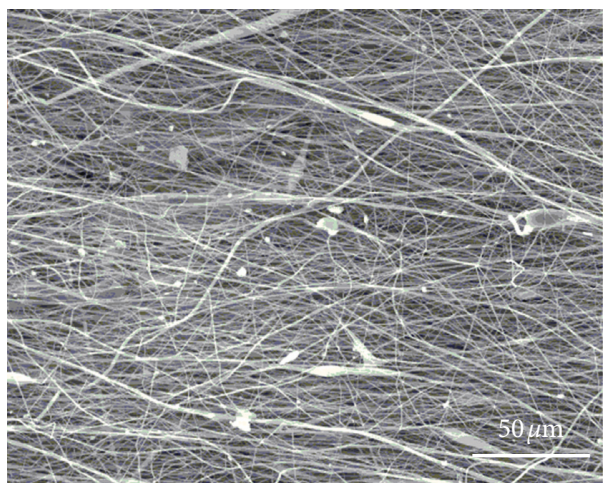

(e)

Figure 3: SEM images of (a) PLA-PBC-0.004GO (scale $10 \mu \mathrm{m}$ ), (b) PLA-PBC-0.01GO (scale $10 \mu \mathrm{m}$ ), (c) PLA-PBC-0.04GO (scale $10 \mu \mathrm{m}$ ), (d) PLA-PBC (scale $10 \mu \mathrm{m}$ ), and (e) PLA-PBC-0.01GO (scale $100 \mu \mathrm{m}$ ). 
with a nanometer fiber membrane on its bottom and held at $37^{\circ} \mathrm{C}$ for $12 \mathrm{~h}$.

\section{Results and Discussion}

Samples from the differential scanning calorimetry (DSC) of the graphene oxide/PLA/PBC nanocomposites were heated from room temperature to $185^{\circ} \mathrm{C}$ at a rate of $10^{\circ} \mathrm{C} / \mathrm{min}$. Figure 1 shows the heating curves of the nanofiber composites. Two melting peaks appeared in the composite fiber membrane because of the physical blending of the two materials, and the crystallization temperature of the $\mathrm{PBC}$ was lower than that of the PLA. The melting peak of pure $\mathrm{PBC}$ and pure PLA was $59.58^{\circ} \mathrm{C}$ and $172.57^{\circ} \mathrm{C}$, respectively, while that of the blend was in between these temperatures. After joining the GO together to improve the melting peak temperature, further volumetric additions of GO increased the number of peaks. The fusion peak between the two independent melting points in the figure shows that the PBC and PLA were well fused with no chemical reaction between them occurring, thus producing the splitting behavior.

In addition, the thermal characteristics of graphene oxide/PLA/PBC nanofibers were investigated by thermogravimetric analysis (TGA), with results shown in Figure 2. Composite GO/PBC/PLA nanofibers demonstrated an improved thermal stability compared with composite materials lacking added GO. When $0.08 \%$ of graphene was added to improve thermal stability, the addition of $0.12 \%$ graphene oxide eventually decreased thermal stability since the graphene oxide content reached a limit in the composite, and thus the highest graphene fraction used was $0.12 \%$.

Scanning electron microscopy (SEM) was used to characterize the graphene oxide distribution and assess the presence of nanofibers produced via electrospinning. Representative SEM images of graphene oxide/PLA/PBC nanofibers with different graphene oxide contents are depicted in Figure 3. Uniform nanofibers were obtained from PLA-PBC-0.004GO, PLA-PBC-0.08GO, and PLA-PBC-0.12GO samples as shown in Figures 3(a)-3(c), respectively. The nanofibers were not dispersed uniformly with pure PLA-PBC, as shown in Figure 3(d), while a uniformly fine dispersion of graphene oxide is shown by the SEM image of Figure 3(e). Beaded nanofibers were also obtained from the sample but ultimately disappeared as the average nanofiber diameter decreased with increasing graphene oxide content. This was due to the increased viscosity of the solutions as the graphene oxide fraction increased.

The FTIR spectra of PLA/PBC fibers and PLA/PBC fibers with added GO (Figure 4) are conspicuously different. The peak at $1751 \mathrm{~cm}^{-1}$ can be attributed to the $\mathrm{C}=\mathrm{O}$ stretching vibration peak of a graphene oxide carboxyl. The absorption peak at $1083 \mathrm{~cm}^{-1}$ belongs to the vibration absorption peak of C-O-C, and the $924 \mathrm{~cm}^{-1}$ absorption peak is near the characteristic absorption peaks of the epoxy group. A few characteristic infrared peaks in spectrum B are clearly shown that are not seen in spectrum A, showing that the PBC/PLA nanofiber membrane was well doped with graphene oxide.

In order to study the anticancer properties and cellular compatibility of the nanofiber membrane in which the

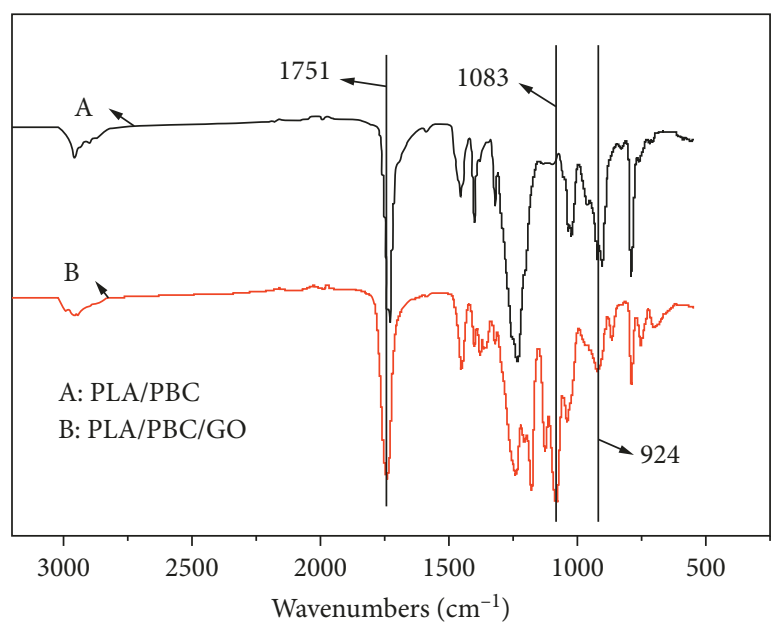

FIGURE 4: FTIR spectra of PLA/PBC nanofibers and GO-contained PLA/PBC nanofibers.

content of graphene oxide was $0.12 \%$, an inverted microscope was used to observe the morphology of the A549 cells on the obtained ultrathin electrospun film, after durations of 1, 3, and 7 days. The result is shown in Figure 5, where Figures 5(b), 5(d), and 5(f) represent the cell morphologies of cultures on the produced ultrathin, electrospun film with drug-loaded Typhonium giganteum, while Figures 5(a), 5(c), and 5(e) are those with films without drug-loaded Typhonium giganteum as a control. The cell morphologies on the control appear spindly, of uniform size, and have smooth cell walls, and the film possesses a good refractive index. The drug-loaded electrospinning film generated cell shrinkage and increased drift, and the number of living cells decreased over time. Hence, the membrane showed good cellular compatibility and could be used for pharmaceutical slowrelease applications to inhibit the proliferation of A549 cells.

As an effective drug carrier, the fiber membranes must be both nontoxic and anticancer. Herein, to explore the cytotoxicity and properties of the prepared membrane fibers, an MTT assay was employed with A549 cells to detect membrane toxicity. The results are shown in Figure 6, with the PBC/PLA/GO membrane showing low cytotoxicity to the A549 cells, the cellular growth rate being not less than $65 \%$ after days 1, 3, and 7 . The toxicity of GO is much lower than that of graphene, and the toxicity of GO is mainly related to dosage. The low concentration of GO does not enter the A549 cells without showing toxicity, and high concentration of GO will slightly damage the cells [22, 23]. Cytotoxicity tests of the loaded Typhonium giganteum $\mathrm{PBC} / \mathrm{PLA} / \mathrm{GO}$ fiber membranes were also performed, revealing that the loaded fiber membranes inhibited the growth of the A549 cells, and the survival rate of A549 cells decreased when the concentration of Typhonium giganteum increased. As long as the membrane contacted the A549 cells, their growth remained inhibited.

\section{Conclusion}

(1) Analysis of the TGA curve indicated that added graphene oxide enhanced the thermal stability more 


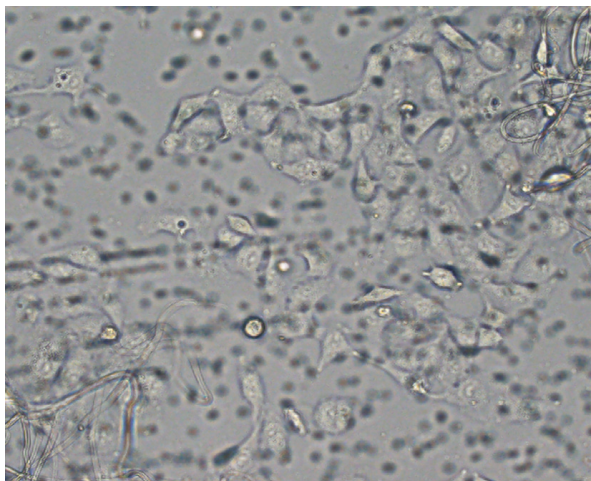

(a)

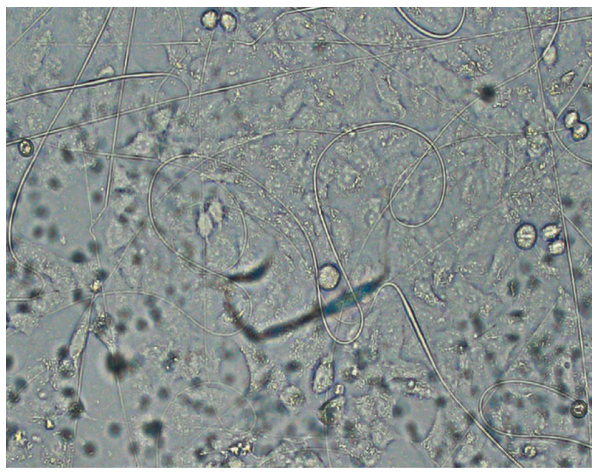

(c)

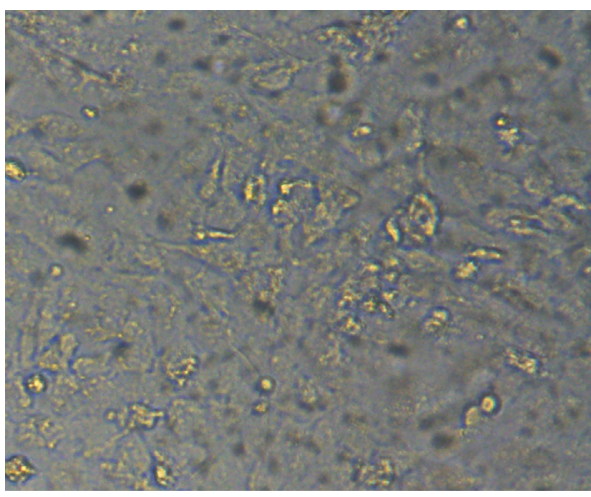

(e)

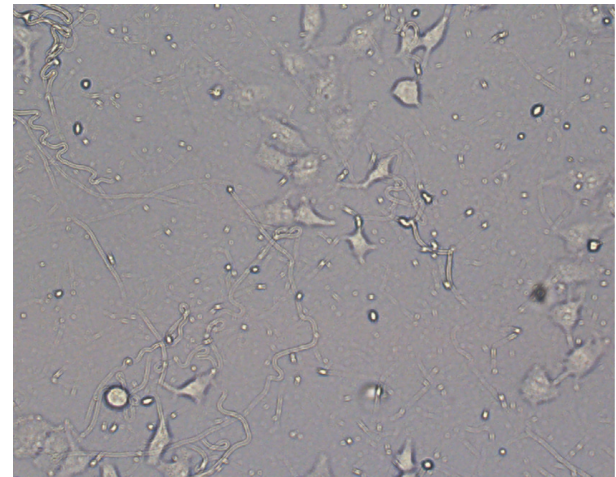

(b)

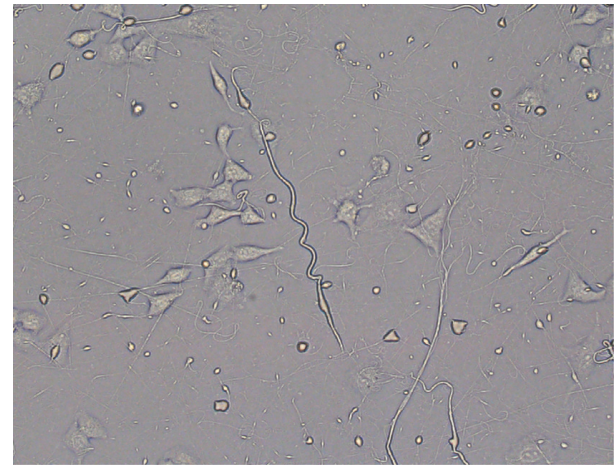

(d)

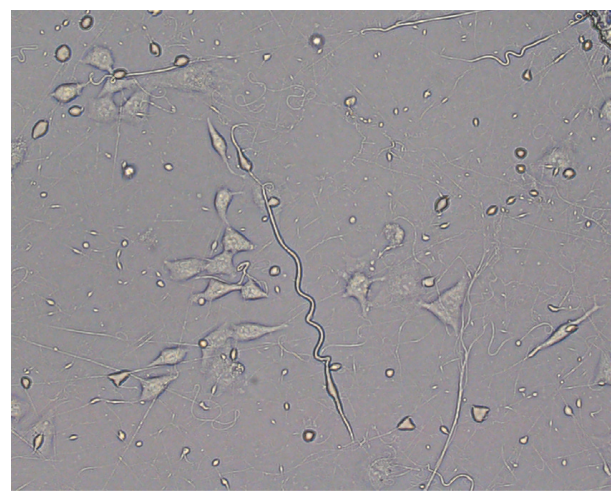

(f)

Figure 5: Inverted microscopy images of A549 lung cancer cells grown onto GO/PLA/PBC nanofibers without drug-loaded Typhonium giganteum (a, c, e) and with drug-loaded Typhonium giganteum GO/PLA/PBC nanofibers (b, d, f) after 1 (a, b), 3 (c, d), and 7 days (e, f).

than that with pure materials; with increased graphene oxide, the material compatibility was very good, demonstrating no peaks. An increase of thermal stability with graphene oxide addition near $0.12 \%$ was likely an upper limit.

(2) Analysis of the DSC curve revealed that the addition of graphene oxide increased the melting peak, which increased with the increasing graphene oxide content. Other cold crystallization peaks also increased.

(3) Analysis of IR spectra indicated that addition of graphene oxide in the composite material showed new peaks near $924 \mathrm{~cm}^{-1}$ and $1083 \mathrm{~cm}^{-1}$, which are the characteristic infrared peaks of oxidized graphene. Therefore, addition of graphene oxide in the composite material was achieved without significant chemical reaction.

(4) SEM images demonstrated that the structure of the nanofiber membrane was the best when the oxide addition fraction was $0.12 \%$. The oxidation of graphene was evenly distributed, and other parts of the fiber membrane were cross-linked.

(5) Inverted microscopy analysis revealed that the morphology of A549 cells cultured on PBC/PLA/GO were spindly, of uniform size, and had smooth cell wall, and the surface had a good refractive index. The loaded Typhonium giganteum PBC/PLA/GO resulted in cell shrinkage and increased drift, and the number of living cells decreased over time. 


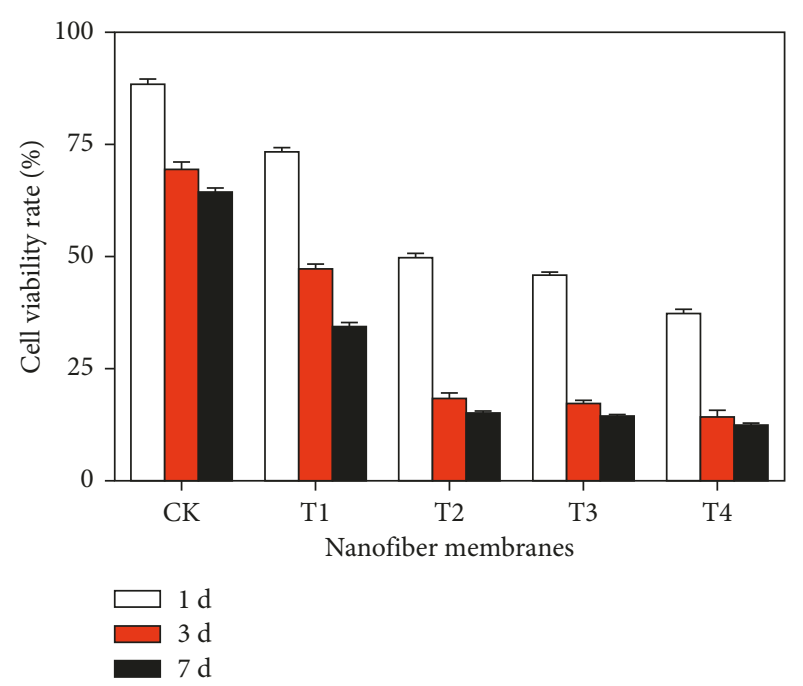

Figure 6: In-vitro cytotoxicity of PVA/PBC/GO fiber membrane on A549 cells.

(6) An MTTassay showed that PBC/PLA/GO fibers have low cytotoxicity, and so a Typhonium giganteum membrane could slowly release pharmaceuticals and inhibit A549 cell growth.

\section{Data Availability}

The data used to support the findings of this study are available from the corresponding author upon request.

\section{Conflicts of Interest}

The authors declare that there are no conflicts of interest.

\section{Acknowledgments}

We gratefully acknowledge the support of Heilongjiang Provincial Department of Education Project (135109214), 2016 Graduate Student Innovation Research of Qiqihar University, China (YJSCX2016-025X), and Heilongjiang Key Lab for Polymer Matrix Composites, Heilongjiang, China.

\section{References}

[1] P. Denis, J. Dulnik, and P. Sajkiewicz, "Electrospinning and structure of bicomponent polycaprolactone/gelatin nanofibers obtained using alternative solvent system," International Journal of Polymeric Materials and Polymeric Biomaterials, vol. 64, no. 7, pp. 354-364, 2015.

[2] Z. Guo, J. Xu, S. Ding, L. Hong, C. Zhou, and L. Li, "In vitro evaluation of random and aligned polycaprolactone/gelatin fibers via electrospinning for bone tissue engineering," Journal of Biomaterials Science, vol. 26, no. 15, pp. 989-1001, 2015.

[3] E. Yan, M. Cao, YuweiWang et al., "Gold nanorods contained polyvinyl alcohol/chitosan nanofiber matrix for cell imaging and drug delivery," Materials Science and Engineering: C, vol. 58, pp. 1090-1097, 2016.

[4] N. Sultana and A. Zainal, "Cellulose acetate electrospun nanofibrous membrane: fabrication, characterization, drug loading and antibacterial properties," Bulletin of Materials Science, vol. 39, no. 2, pp. 337-343, 2016.

[5] E. Yan, M. Cao, Y. Wang et al., "Degradable polyvinyl alcohol/ poly(butylene carbonate) core-shell nanofibers for chemotherapy and tissue engineering," Materials Letters, vol. 167, pp. 13-17, 2016.

[6] M. A. Alvarez-Perez, V. Guarino, V. Cirillo, and L. Ambrosio, "Influence of gelatin cues in PCL electrospun membranes on nerve outgrowth," Biomacromolecules, vol. 11, no. 9, pp. 2238-2246, 2010.

[7] V. Cirillo, B. A. Clements, V. Guarino, J. Bushman, J. Kohn, and L. Ambrosio, "A comparison of the performance of mono- and bi-component electrospun conduits in a rat sciatic model," Biomaterials, vol. 35, no. 32, pp. 8970-8982, 2014.

[8] K. T. Shalumon, N. S. Binulal, N. Selvamurugan et al., "Electrospinning of carboxymethyl chitin/poly(vinyl alcohol) nanofibrous scaffolds for tissue engineering applications," Carbohydrate Polymers, vol. 77, no. 4, pp. 863-869, 2009.

[9] C. Seok Ki, D. H. Baek, K. D. Gang, K. H. Lee, I. C. Um, and Y. H. Park, "Characterization of gelatin nanofiber prepared from gelatin-formic acid solution," Polymer, vol. 46, no. 14, pp. 5094-5102, 2005.

[10] L. Zhang, A. Aboagye, A. Kelkar, C. Lai, and H. Fang, "A review: carbon nanofibers from electrospun polyacrylonitrile and their applications," Journal of Materials Science, vol. 49, no. 2, pp. 463-480, 2014.

[11] Y. Dai, W. Liu, E. Formo, Y. Sun, and Y. Xia, "Ceramic nanofibers fabricated by electrospinning and their applications in catalysis, environmental science, and energy technology," Polymers for Advanced Technologies, vol. 22, no. 3, pp. 326-338, 2010.

[12] T. J. Sill and H. A. Von Recum, "Electrospinning: applications in drug delivery and tissue engineering," Biomaterials, vol. 29, no. 13, pp. 1989-2006, 2008.

[13] T. Zhu, H. Wu, and L. Zhang, "A survey of studies on rhizoma typhonii,” Chin. Arch. Tradit. Chin.Med., vol. 26, pp. 1176-1178, 2008.

[14] D. Hua, K. Rui, H. L. Gang, and Z. G. Wang, "The study on the expression of HORN LIAN to angiogenic factor BFGF in the anti-tumor effect on $\mathrm{H} 22$ tumor-bearing mice," Inf. Tradit. Chin.Med., vol. 28, pp. 97-100, 2011.

[15] S. Q. Wang, H. Ni, J. Wang, and L. Chen, "The inhibition effects of Typhonium giganteum engl. on hepatocarcinoma cell," Chinese Journal of Cell Biology, vol. 25, pp. 185-188, 2003.

[16] L. M. Wang, B. Ye, Z. J. Zhao, and S. Y. Li, "Inhibition of proliferation and induction of apoptosis in MCF-7 cell by Typhonium giganteum Engl," Journal of Shenyang Agricultural University, vol. 40, pp. 174-177, 2009.

[17] S. Q. Wang, H. Ni, H. Cheng, G. L. Wang, T. S. Wang, and L. Chen, "Detection of differentially expressed genes in hepatocellularcarcinoma cells SMMC-7721 treated with Typhonium giganteum extract by mRNA differential display," Zhongguo Zhong Yao Za Zhi, vol. 29, no. 10, pp. 974-977, 2004.

[18] G. Shan-shan and Y. Hai-shi, "Research progress in antitumor effects of rhizoma typhonii," China Cancer, vol. 22, no. 6, pp. 451-456, 2013.

[19] X. Y. Yang, X Y. Zhang, Z. F. Liu et al., "High-efficiency loading and controlled release of doxorubicin hydrochloride on graphene oxide," Journal of Physical Chemistry C, vol. 112, no. 45 , pp. 17554-17558, 2008.

[20] S. L. Wu, X. D. Zhao, Y. H. Li et al., "Adsorption properties of doxorubicin Hydrochloride onto graphene oxide equilibrium, 
kinetic and thermodynamic studies," Materials, vol. 6, no. 5, pp. 2026-2042, 2013.

[21] X. Y. Yang, X. Y. Zhang, Y. F. Ma et al., "Superparamagnetic graphene oxide- $\mathrm{Fe}_{3} \mathrm{O}_{4}$ nanoparticles hybrid for controlled targeted drug carriers," Journal of Materials Chemistry, vol. 19, no. 18, pp. 2710-2714, 2009.

[22] C. H. Lu, C. L. Zhu, J. Li et al., "Using graphene to protect DNA from cleavage during cellular delivery," Chemical Communications, vol. 46, no. 18, pp. 3116-3118, 2010.

[23] Y. L. Chang, S. T. Yang, J. H. Liu et al., "In vitro toxicity evaluation of graphene oxide on A549 cells," Toxicology Letters, vol. 200, no. 3, pp. 201-210, 2011. 

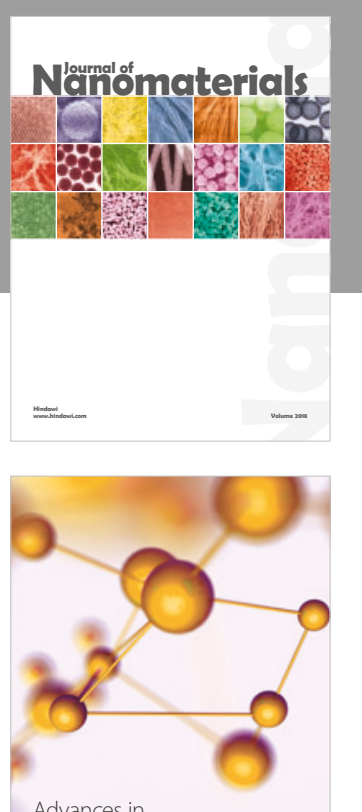

Physical Chemistry
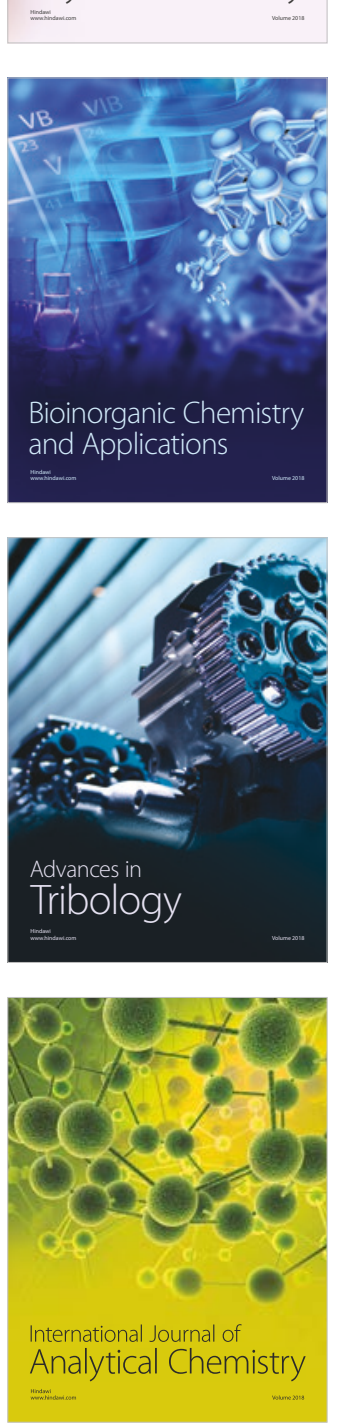

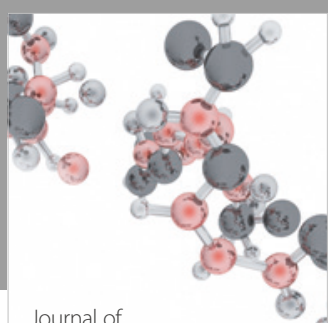

Analytical Methods

in Chemistry

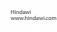

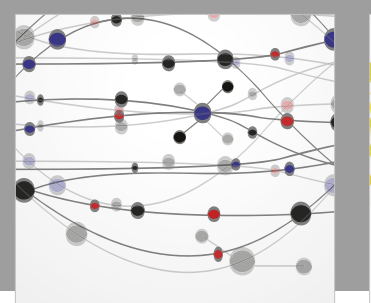

The Scientific World Journal

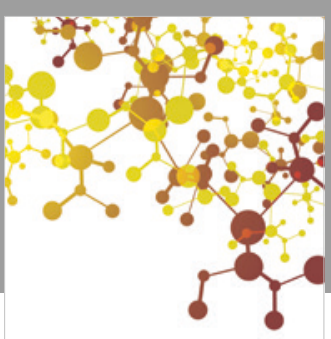

Journal of

Applied Chemistry
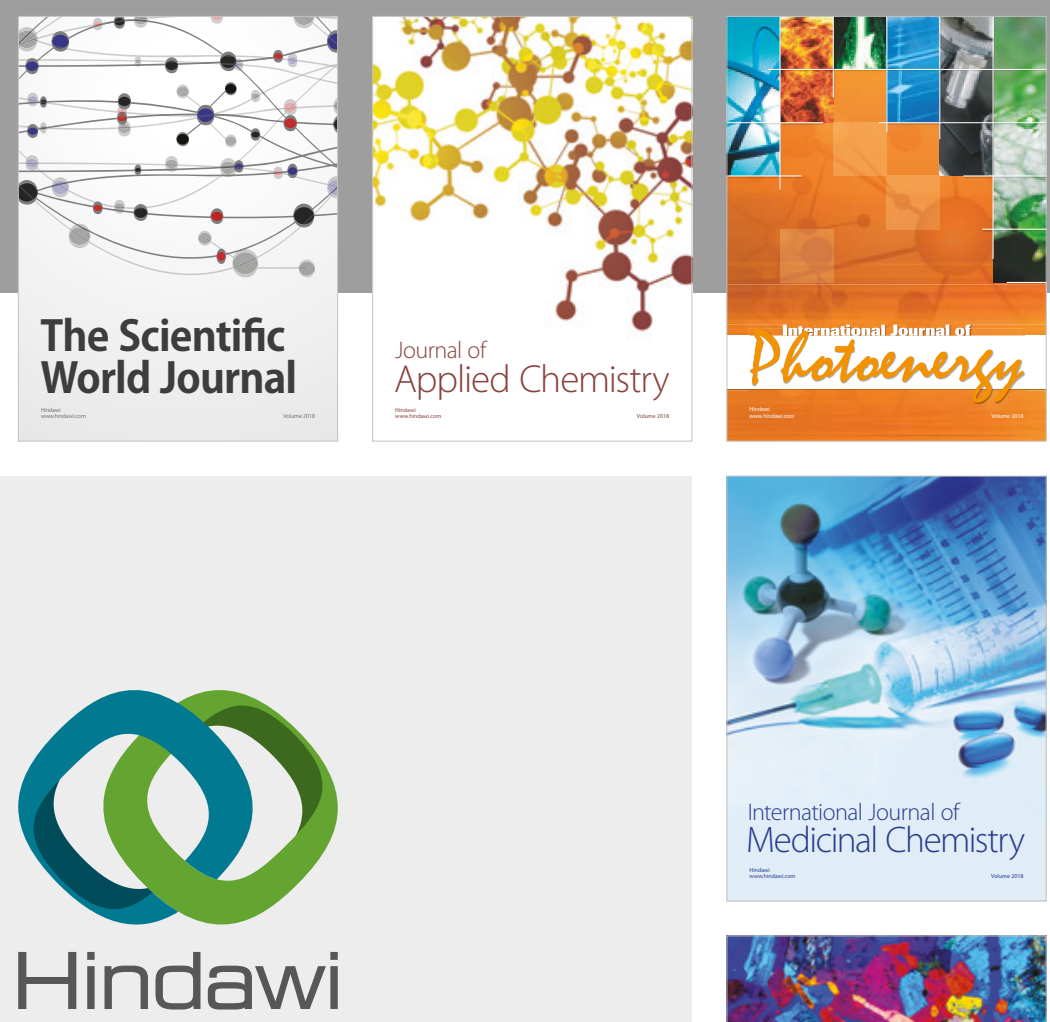

Submit your manuscripts at

www.hindawi.com
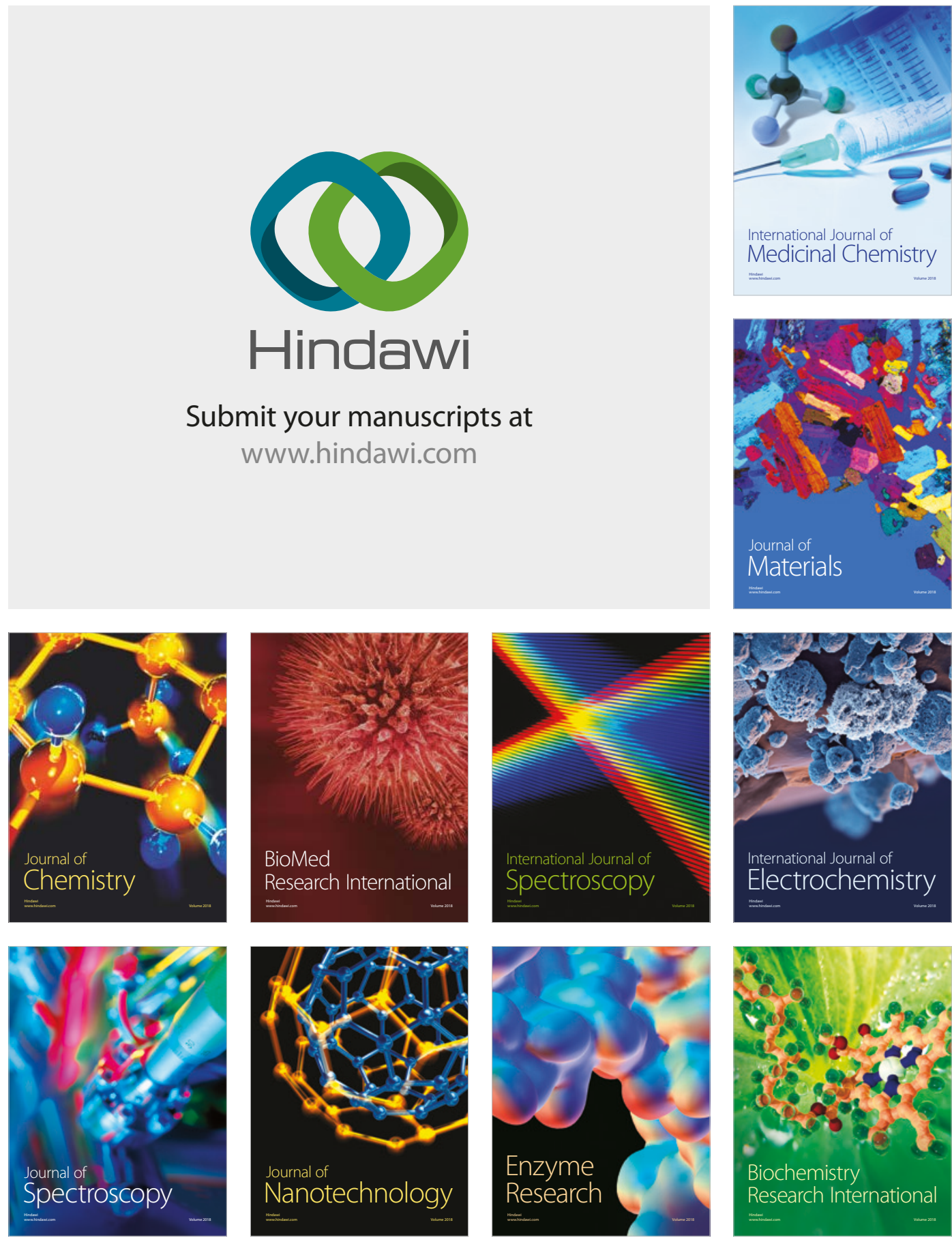
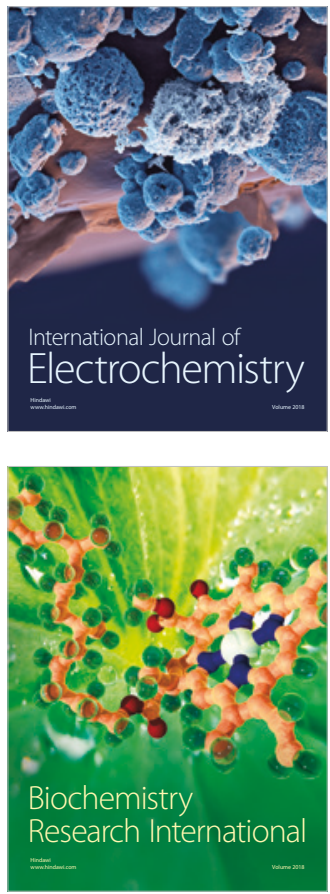